\title{
Marketing and the Junk Fax Prevention Act: What now?
}

Received (in revised form): 6th November, 2007

\section{Gwen Fontenot}

is an assistant professor of marketing and Department Head in the Department of Marketing and Hospitality at the University of Louisiana at Lafayette. She has held several senior marketing research positions in industry and has owned and operated her own marketing research firm for over ten years. She has authored and co-authored numerous papers in refereed academic and trade journals such as Journal of Targeting, Measurement, and Analysis for Marketing, Journal of Marketing Channels, Total Quality Management Journal and Quality Progress.

\section{Raj Srivastava}

is an associate professor of marketing in the Department of Marketing and Management at the Middle Tennessee State University. He has also taught at the University of Louisiana at Lafayette. He has authored or co-authored papers in refereed academic journals such as Journal of the Academy of Marketing Science, Journal of Personal Selling and Sales Management, Journal of Marketing Channels and Industrial Marketing Management, among others.

\section{Anne Keaty}

holds a Juris Doctorate from Louisiana State University and is a professor of legal studies in the B.I. Moody, III College of Business Administration, where she has been teaching since 1981. She holds the Ramon E. Billeaud Professorship in Business. Over her teaching career, she has developed new law courses such as Mineral Law and Cyberlaw. She has published papers in both legal and business journals, and is a contributing editor for the Bisk CPA Review.

Keywords Junk Fax Prevention Act, law regarding facsimiles, fax and law, FCC regulations regarding facsimiles, Federal Communications Commission and facsimiles, advertising and facsimiles

Abstract The Junk Fax Prevention Act (JFPA), which became effective on 5th July, 2005, has revived the junk-fax as a viable marketing tool. The new Federal Communications Commission (FCC) regulations, which became effective on 1st August, 2006, clarify when and to whom a fax may legally be sent by defining terms such as an 'unsolicited advertisement' and an 'established business relationship.' These clarifications allow the businessperson much more certainty and latitude in the use of facsimile advertising. This paper examines the new law and regulations, as well as the FCC enforcement actions and court cases that have arisen since the enactment of the JFPA.

Journal of Database Marketing \& Customer Strategy Management (2007) 15, 49-55.

doi:10.1057/palgrave.dbm.3250068; published online 10 December 2007

Raj Srivastava

Management and Marketing Department Jennings A. Jones College of Business Middle Tennessee State University PO Box 442, Murfreesboro TN 37132, USA Tel: + 16158982780 ; Fax: +1 615898 5308; e-mail: raj@mtsu.edu

\section{INTRODUCTION}

The Junk Fax Prevention Act (JFPA), ${ }^{1}$ which became effective on 5th July, 2005, makes it 'unlawful for any person within the United States, or any person outside the United States if the recipient is within the United States ... to use any telephone facsimile machine, computer, or other device to send, to a telephone facsimile machine, an unsolicited advertisement.' The law directed the Federal Communications Commission (FCC) to create federal regulations to implement this law. ${ }^{2}$ The FCC regulations became effective on 
1st August, 2006. This paper is an examination of questions that have arisen since the enactment of the FCC regulations. What is an 'unsolicited advertisement'? What is an 'established business relationship' that will qualify as an exemption to an unsolicited advertisement and how long does it last? What new interpretations of this law and its rules can be gleaned from the FCC enforcement actions and the court cases that have arisen since the enactment of the JFPA?

\section{HISTORY OF THE JFPA}

The JFPA is an amendment to the Telephone Communications Privacy Act of 1991 (TCPA). ${ }^{3}$ In 1991, the TCPA defined 'unsolicited advertisement' as 'any material advertising the commercial availability or quality of any property, goods, or services which is transmitted to any person without that person's prior express invitation or permission (emphasis ours). ${ }^{4}$ The new law directed the FCC to create regulations to implement the law, which the FCC did by drawing up regulations to prohibit automatic telephone dialing systems and to require that the sender be clearly identified in the facsimile. ${ }^{5} \mathrm{~A}$ footnote in the FCC order accompanying the regulations, however, stated: 'We note, however, that facsimile transmission from persons or entities that have an established business relationship with the recipient can be deemed to be invited or permitted by the recipient (emphasis ours). ${ }^{6}$

When these regulations began to be enforced, the courts were divided on the authority of this footnote. The majority of courts discounted the footnote as inconsistent with the plain language of the TCPA. Some courts upheld the FCC's exemption to the general prohibition on unsolicited advertisements delivered via facsimile. So much ambiguity arose that in 2003 the FCC decided to eliminate the 'established business relationship (EBR)' exemption. This change never took place as the FCC, noting industry alarm and expecting Congressional action on the subject, stayed the effectiveness of the change five times. In 2005, Congress amended the TCPA by passage of the JFPA.

\section{THE LAW TODAY}

The JFPA of 2005

- codified the exemption of an EBR to the prohibition on sending unsolicited facsimile advertisements;

- provided a definition of the EBR;

- went further to state that a facsimile could be sent in an EBR even if the recipient had not provided an express invitation or permission;

- changed the definition of 'unsolicited advertisement' such that an 'express written permission' did not have to be in writing;

- called for the FCC to make a report to Congress every year on its enforcement of this law;

- granted new rulemaking authority to the FCC to implement the law and incidentally called for the FCC to

- to amend its regulations to comply with the EBR exemption;

- create opt-out rights for recipients and opt-out disclosures in the facsimile advertisements;

- determine the shortest reasonable time for the sender to comply with the opt-out request;

- decide whether trade associations and professional organisations should have to comply with the opt-out provision; and

- consider whether the EBR should have a time limit. ${ }^{7}$

\section{THE FCC REGULATIONS}

The FCC promulgated regulations to implement the JFPA in May 2006, which regulations became effective on 1st August, $2006 .{ }^{8}$ The new regulations provide that it is unlawful to send unsolicited advertisements to any fax machine, 
including those at both businesses and residences, without the recipient's prior express invitation or permission. There are two exceptions to the requirement of obtaining the recipient's express permission: (1) the sender is able to show he or she is in an EBR with the recipient or (2) the sender has obtained the recipient's fax number by any of certain methods whereby it can be presumed the recipient has provided the number to the sender, like in the recipient's own advertisement on the internet.

\section{TERMS DEFINED}

The FCC explained and limited the terms in this regulation as follows: ${ }^{9}$

- An advertisement is 'any material advertising the commercial availability or quality of any property, goods, or services.'

- Free offers for products or services that are part of a promotion to sell are considered advertisements.

- Offers for free publications containing products or services available for purchase are advertisements.

- Messages whose primary purpose is to deliver information (newsletter to neighbourhood) may contain a small amount of advertising and not be considered advertisements.

- Surveys that serve as a pretext to an advertisement are considered advertisements.

- Unsolicited is defined as being sent 'without the person's prior express invitation or permission, in writing or otherwise.'

- Express permission can be written, oral, or electronic.

- It cannot be requested by an unsolicited fax.

- A sender may include on an application form that, by providing a number, the individual or business agrees to receive faxes.
- It cannot be in the form of a negative option. (If we don't hear from you, we will assume you give permission.)

- The burden is on the sender to prove it has received permission, whatever the method of transmission.

- Exception to express permission: Established business relationship (EBR). An EBR is 'a prior or existing relationship formed by a voluntary two-way communication between a person or entity and a business or residential subscriber with or without an exchange of consideration, on the basis of an inquiry, application, purchase, or transaction by the business or residential subscriber regarding products or services offered by such a person or entity, whose relationship has not been previously terminated by either party.'

- The FCC gives examples of an 'inquiry, application, purchase, or transaction' that can be the basis of the proper two-way communication that is necessary for an EBR to exist.

- An inquiry

- The inquiry or application must be about products or services offered by the entity.

- Inquiries about store locations or the identity of the fax sender would not qualify, nor would a mere visit to a website by a recipient without additional steps to request information or provide contact information.

- A transaction is a message whose purpose is to facilitate, complete, or confirm a commercial transaction that the recipient has previously agreed to enter into with the sender. Examples of transactions that would serve as a basis of the two-way communication necessary for the EBR are:

- confirmation of a purchase; account balance information;

- notification of change in terms or features regarding an account subscription, membership, loan or 
comparable ongoing relationship, in which the recipient has already purchased or is currently using the facsimile sender's product or service;

- communications to facilitate a loan already in progress, such as property appraisals, summary of closing costs, disclosures if their purpose is to complete a financial transaction;

- communications from a trade show organiser to an exhibitor, if the exhibitor has already agreed to attend;

- notices soliciting bid proposals (containing no offers for services or products); and

- communication of a travel itinerary for a trip a customer has agreed to take or is in the process of negotiating.

Messages must relate specifically to existing accounts and ongoing transactions and should not concern new products or services. The sender has the burden of proving an EBR and may prove it by showing purchase agreements, sales slips, applications and inquiry records, and the like.

- Exceptions to express permission outside of an EBR exist when the sender obtains the fax number in one of the following ways:

- the recipient itself voluntarily provides the fax number to the sender;

- the sender obtains the fax number from the recipient through, for example, an application contact information form or membership renewal form;

- the sender obtains the fax number from the recipient's own directory, advertisement, or site on the internet, unless the recipient has noted on such materials that it does not accept unsolicited advertisements at the fax number in question; or
- the sender has taken reasonable steps to verify that the recipient consented to have the number listed, if obtained from a directory or other source of information compiled by a third party.

- If the sender has an EBR before the passage of the JFPA in July 1995, the sender does not have to demonstrate how the number was obtained.

\section{EBR - AFFILIATES, THIRD-PARTY SENDERS, NO TIME LIMIT}

The voluntary two-way communication that exists between the sender and the recipient does not extend to the sender's affiliates (subsidiaries, parent companies, etc), nor does it extend to the sender's fax broadcaster. The fax broadcaster cannot claim an EBR because he is communicating with his clients' recipients. The FCC did set a time limit on the EBR, but stated it would revisit the issue within a year to see whether the EBR duration was inconsistent with consumer reasonable expectations. ${ }^{10}$

\section{OPT-OUT INFORMATION}

Under the new rules, senders must provide the following opt-out information in all facsimiles:

- Senders must state clearly and conspicuously on the first page of the advertisement that the recipient may make a request to the sender not to send any future faxes and that failure to comply with the request within 30 days is unlawful.

- The sender must include a telephone number, fax number, and a cost-free mechanism (including a toll-free telephone number, local number for local recipients, toll-free fax number, website address, or e-mail address) that the recipient can use to opt out of faxes.

- These numbers and cost-free mechanisms must be available for opt-out requests 24 hours a day, seven days a week. 
- The sender must try to comply with the opt-out request as soon as possible, but, at the latest, within 30 days.

- The opt-out request should identify the fax numbers it concerns.

- Senders are liable, even if the sender did not physically send the faxes because the faxes are sent by a third party.

- The third parties and fax broadcasters can be liable, depending on the degree of involvement. Involvement includes supplying fax numbers, providing a source of fax numbers, advising how to comply with the junk fax rules or the legality of sending faxes to specific numbers. If the third-party sender participates in the creation of the message, the third party must provide its name on the fax.

- There is no 'do not call list' for faxes.

\section{EXEMPT ENTITIES}

After notice and comment, the FCC has determined that small businesses are not exempt from the opt-out requirement and tax-exempt trade organisations and professional organisations are likewise not exempt, but these entities may use the EBR as a valid exemption. If the nonprofit fax message is not an advertisement, but a message involving political or religious discourse or a request for a donation to a political action committee, a political campaign or a charitable organisation, the message is not considered an advertisement and does not have to comply with the opt-out provisions.

\section{FCC ENFORCEMENT ACTIONS ${ }^{11}$}

Under the JFPA, individuals who receive unsolicited facsimiles are permitted to seek a judicial remedy or contact the FCC to obtain an enforcement action. If the individual brings a private action, he or she may recover $\$ 500$ or the actual monetary loss suffered for each unsolicited fax. If the FCC brings the action, it may fine the violator up to $\$ 11,000$ for each facsimile transmitted in violation of the law; however, actually collecting the fines is the province of the Justice Department. According to the 9th July, 2005 to 9th July, 2006 report filed by the FCC with Congress, the enforcement procedure consists of several steps. Individuals and businesses can submit their complaints about the receipt of unsolicited facsimile advertisements to the FCC by e-mail, postal mail, fax, telephone, or the internet. A single complaint often refers to multiple unsolicited facsimiles. ${ }^{12}$ During the one-year period of the report, the FCC received 47,704 junk fax complaints representing 102,000 alleged violations. Eighty-five per cent of the complaints received were fully addressed by the FCC, meaning that, as to this 85 per cent, a complaint was issued, or there was no way to identify the alleged violator, or the complaint did not contain the required information to support a citation. In the report period, 125 citations were issued against entities using telephone numbers associated with 59 per cent of the potentially actionable violations.

If the sender complies with the citation and discontinues sending unsolicited facsimiles, the matter is dropped. If the sender does not comply or respond, the FCC issues a notice of Apparent Liability for Forfeiture (NAL), followed by a Forfeiture Order. If the fine is not paid, the FCC turns the case over to the Justice Department for collection. During the 2005-2006 report period, the FCC issued

- One Notice of Apparent Liability for Forfeiture (NAL) proposing a civil forfeiture penalty of $\$ 776,500$ against First Choice Healthcare, Inc. (First Choice) for 98 unsolicited facsimile advertisements sent to 37 businesses and individuals without either the recipients' prior express invitation or permission or an EBR. First Choice filed a response to the NAL. 
- One Forfeiture Order of $\$ 22,000$ on Elf Painting and Wallpapering (ELF) (on 31st July, 2006) for sending five unsolicited facsimile advertisements to five consumers. ELF had not paid or responded and the FCC requested the Department of Justice to initiate a proceeding against ELF to collect the forfeiture penalty on 31st July, 2006.

- A $\$ 153,000$ NAL against the National Business Information Corporation (NBIC) (on 20th September, 2006) for 34 unsolicited facsimile advertisements sent by NBIC to eight consumers without permission or an EBR.

According to the United States Government Accountability Office (GAO), which was directed by Congress to report on the FCC's enforcement of the junk fax laws, the FCC enforcement efforts are not in line with number of consumer complaints. ${ }^{13}$ '[C]onsumer frustration with junk faxes is evident in the rapidly increasing number of complaints and in the time the consumers are willing to take to seek relief from this type of unsolicited advertising' (Goldstein, ${ }^{13}$ pp. 30-31). While the FCC has multiple methods for consumers to submit their complaints and promptly acknowledges receipt of most of them, it has taken formal enforcement actions against relatively few junk faxers. 'In 2000, FCC recorded about 2,200 junk fax complaints; in 2005 it recorded over 46,000. Using its procedures to review the complaints, FCC's

Enforcement Bureau (EB) issued 261 citations (ie, warnings) from 2000 through 2005. IEB has ordered six companies to pay forfeitures for continuing to violate the junk fax rules after receiving a citation. The six forfeitures totaled over $\$ 6.9 \mathrm{~m}$, none of which has been collected by the Department of Justice for various reasons' (Goldstein, ${ }^{13}$ pp. $2-3$ ). Some of the reasons are that the business has gone bankrupt, disappeared, or was out of the jurisdiction of the Justice Department.
The GAO Report indicates that the FCC's data processing procedures cause many complaints to be left out of consideration entirely. The FCC's procedures call for a copy of the illegal fax to be attached to the complaint in order to process the complaint. This requirement to attach the fax is not clear to the consumers sending in their complaints, or the complaining consumer does not know how to attach the offending fax. Furthermore, once the complaints are gathered, the FCC procedure is to transfer them to its own spreadsheet, which leaves out all the complaints not accompanied by the offending facsimiles. Therefore, the FCC processes from this point on omit many complaints altogether, resulting in many complaints not being considered when the FCC analyses its data to see what the real problem areas are for management purposes. Those complaints omitted may be those that are complaining about unsuccessful attempts to opt out, rather than the fact that the fax should not have been sent in the first place. The GAO cites several management problems, including resource constraints, poor data management, and the increasing ability of the violators to hide their fax numbers, all of which plague the FCC enforcement efforts. Because of the GAO Report, it seems likely that the FCC will be more aggressive than it has been to date in its enforcement of violations. ${ }^{7}$

\section{COURT CASES}

In Phillips Randolph Enterprises v. Adler-Weiner Research Chicago, ${ }^{14}$ the plaintiff claimed that the following invitation to business owners or business decision makers to participate in a research discussion was an advertisement.

'New HEALTHCARE PROGRAM, sponsored by The Chicagoland Chamber of Commerce ... HONORARIUM: $\star \star \star \$ 200.00 \mathrm{cash}^{\star \star \star}$. If you are interested in participating in this research study, please call to see if you 
qualify between the hours of 9:00 and 4:30.' The plaintiff claimed that the invitation was really a pretext to advertise commercial products and services. The court disagreed and found that it was not a 'commercially available service' but a research study. On the pretext issue, the court found that the plaintiff did not allege that any products or services would be commercially available at the seminar and that the invitation was not open to the public, but made clear that individuals interested in participating in the research study must be qualified or prescreened.

The JFPA provides that states may enact restrictions on intrastate unsolicited facsimile transmissions. The court in Chamber of Commerce of the United States of America v. Lockyer $^{15}$ agreed with the defendant that the state restriction of interstate facsimile transmissions are preempted by the federal law, but stated that state law may govern intrastate transmissions. In State of Missouri v. Progressive Business Publications, ${ }^{16}$ the defendant claimed that it had an existing business relationship with the plaintiff. The plaintiff placed an order with defendant on 12th April, 2005 for the newsletter 'Legal Update for Teachers.' When he placed this order, the plaintiff provided to the defendant the month and day of his birthday and provided his fax number. The court agreed that an EBR existed, which made faxes to the plaintiff legal under the TCPA.

\section{CONCLUSION}

The JFPA of 2005 in effect 're-establishes junk-fax as a viable marketing tool, which is what the TCPA had originally sought to ban' (Laudina, ${ }^{17}$ p. 849). By codifying the
EBR, extinguishing the requirement for written permission, and putting the burden to opt out on the recipient, the new law and the FCC rules have made it easier for businesses to assert that they have the consumer's permission to send an advertisement in a fax.

\section{References and Notes}

147 U.S.C. $\$ 227$ (b)(1)(c) (West \& Supp. 2006).

247 U.S.C. $\$ 227$ (b)(2); Rules and Regulations Implementing the Junk Fax Protection Act of 2005, 71 Fed. Reg. 42297 (26th July, 2006) (codified at 47 C.F.R. pt. 64).

347 U.S.C. $\$ 227($ b) (1)(C)(West 2001 \& Supp. 2006).

447 U.S.C. $\$ 227(\mathrm{a})(5)$ (West 2001 \& Supp. 2006).

57 F.C.C.R 8752 (16th October, 1992) (amending 47 C.R.F. $\$ 64.1200$ and 47 C.F.R. $\$ 68.318(d)(3))$.

6 Id. at 8779 n. 87.

7 Goodman, M. and Nooan, J. (2007) 'Fax, e-mail, and telephone: Federal Regulation of Marketing methods', The Business Lawyer, Vol. 62, pp. 575-586.

847 C.F.R. pt. 64.

9 Federal Communication Commission Rules and Regulations Implementing the Telephone Consumer Protection Act of 1991, CG Docket No. 02-278, Junk Fax Prevention Act of 2005, CG Docket No. 05-338, Report and Order and Third Order on Reconsideration; Adopted 5th April, 2006, Released 6th April, 2006.

10 Id.

1147 U.S.C. $227(\mathrm{~g})$. (The FCC must submit an annual report to Congress regarding enforcement of the commission rules relating to the transmission of unsolicited facsimiles.).

12 Chief, Enforcement Bureau, 'Annual Report on Unsolicited Facsimile Advertisements,' released 4th January, 2007.

13 Goldstein, M. (2006) 'Telecommunications: Weaknesses in procedures and performance management Hinder Junk Fax Enforcement: GAO -060425', GAO Reports, April, pp. 1-48.

142007 WL 293928, N.D. Ill, 30th January, 2007 (No. 06 C5111).

152006 WL 462482 (E.D. Cal. 2006).

162007 WL 627848 (W.D. Mo.2007).

17 Laudina, M. R. (2007) 'To fax or not to fax: Analysis of the Regulations and Potential Burdens Imposed by the Junk Fax Prevention Act of 2005', Seton Hall Law Review, Vol. 37, pp. 835-862. 